\title{
Pharmaceutically Active Compounds in Wastewater Treatment Plants: Electrochemical Advanced Oxidation as Onsite Treatment
}

\author{
Ana Rita Ferreira ${ }^{1}$, Paula Guedes ${ }^{1,2}$, Eduardo P. Mateus ${ }^{1}$, Alexandra B. \\ Ribeiro ${ }^{1}$ and Nazaré Couto ${ }^{1}$
}

${ }^{1}$ CENSE - Center for Environmental and Sustainability Research, Department of Environmental Sciences and Engineering, NOVA School of Science and Technology, NOVA University Lisbon, Caparica 2829-516, Portugal ${ }^{2}$ Instituto de Tecnologia Química e Biológica António Xavier, Universidade Nova de Lisboa, Oeiras 2780-157, Portugal

\subsection{Introduction}

\subsubsection{Emerging Organic Contaminants}

Emerging organic contaminants (EOCs) or contaminants of emerging concern can be defined as naturally occurring, manufactured, or manmade chemicals or materials whose associated risks cannot be properly evaluated due to the lack of data about their environmental fate and ecotoxicological or toxicological effects [1, 2]. A contaminant remains "emerging" as long as there is a scarcity of information in the scientific literature about the associated potential risks it could cause [1, 2].

EOCs broadly include "lifestyle compounds," personal care compounds, pharmaceuticals including hormones, and plasticizers [3]. Pharmaceutical products account for $70 \%$ of the approximately 4500 chemical compounds available in the world, and the production of pharmaceutical compounds and other medicines is still increasing [4]. Over the years, population growth and the development of new medicines to prevent or cure diseases with unknown fates and effects on the environment has made these compounds deserve special attention [5].

Over the last few decades, the subject of EOCs has become a worldwide issue of increasing environmental concern, and intensive research has been carried out on a range of different topics such as their occurrence and fate in the environment as well as treatment methods. A total of 117 papers were published in 2013 (Figure 6.1), and the number of studies has continued to increase since then to 330 in 2019 (almost two times more than five years before).

\subsubsection{Occurrence and Fate of EOCs}

One of the primary current worldwide concerns is the growth of pollution due to EOCs arising from many urban, industrial, and agricultural activities. Technological

Electrokinetic Remediation for Environmental Security and Sustainability, First Edition.

Edited by Alexandra B. Ribeiro and M.N.V. Prasad.

(c) 2021 John Wiley \& Sons Ltd. Published 2021 by John Wiley \& Sons Ltd. 


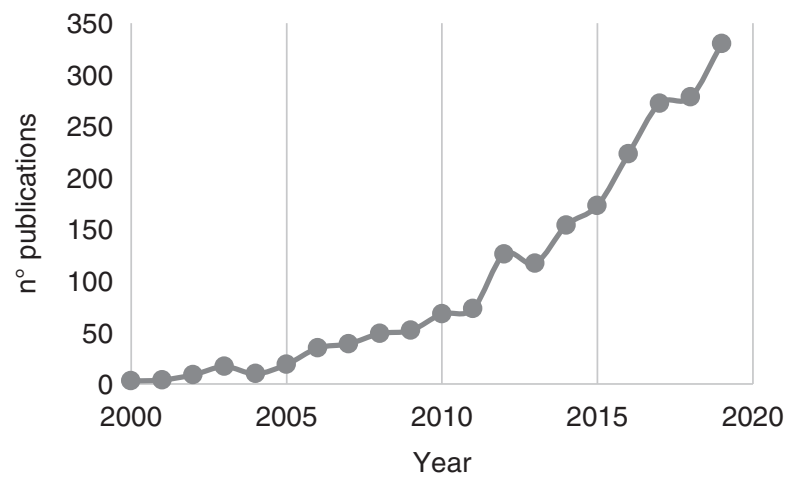

Figure 6.1 Number of publications on emerging organic contaminants from 2000 to 2019 .

advances in analytical instrumentation and techniques have enabled researchers to detect and quantify EOCs in different environmental compartments (soil, air, and water) [6-8].

EOCs are now commonly detected in the environment due to their constant introduction through the disposal of wastewater, biosolids, and manure (Figure 6.2). Waste streams from hospitals, wastewater treatment plants (WWTPs), and sewage treatment plants have been identified as significant contributors to environmental contamination with EOCs [3, 9-11]. Besides the ubiquitous occurrences of EOCs in the environment, significant and measurable concentrations of ibuprofen, diclofenac, and carbamazepine were also found in drinking waters, e.g. [12, 13]. Surface water, groundwater, and soils are interrelated, and upon arrival in the environment, EOCs can undergo significant transformation including (bio)degradation, sorption at the sediment, and transport in the aqueous phase. This transformation depends on EOC physicochemical properties such as volatility, polarity, adsorption properties, persistence, and the properties of the interacting compartments: for example, the presence of a community of organisms that can transform the contaminants through metabolic networks and the bioavailability of contaminants, especially in sediments and soil $[14,15]$. Generally, compounds with octanol/water partition coefficient $\left(\log \mathrm{K}_{\text {ow }}\right.$ ) lower than 3.0 are not expected to be adsorbed significantly to the particles, but compounds with relatively high Log $\mathrm{K}_{\text {ow }}$ values and $\mathrm{pKa}$ values below the $\mathrm{pH}$ of the wastewater are expected to be dissociated in the aqueous phase and not bound to the particles. Despite known chemical properties, it is difficult to predict their behavior in the environment as it depends on several variables [16].

In addition to direct sources of EOCs in the environment, other potential routes for these compounds may be considered. For example, reusing treated wastewater for irrigation in agriculture can also represent a risk to human health as EOCs might transfer to soil, potentially increasing the risk of consumption as they are not regulated and can be accumulated within crop plants. This fact has been already reported by several studies [15-20]. Malchi et al. [21] found 14 different EOCs, such as carbamazepine, caffeine, clofibric acid, diclofenac, ibuprofen, ketoprofen, 


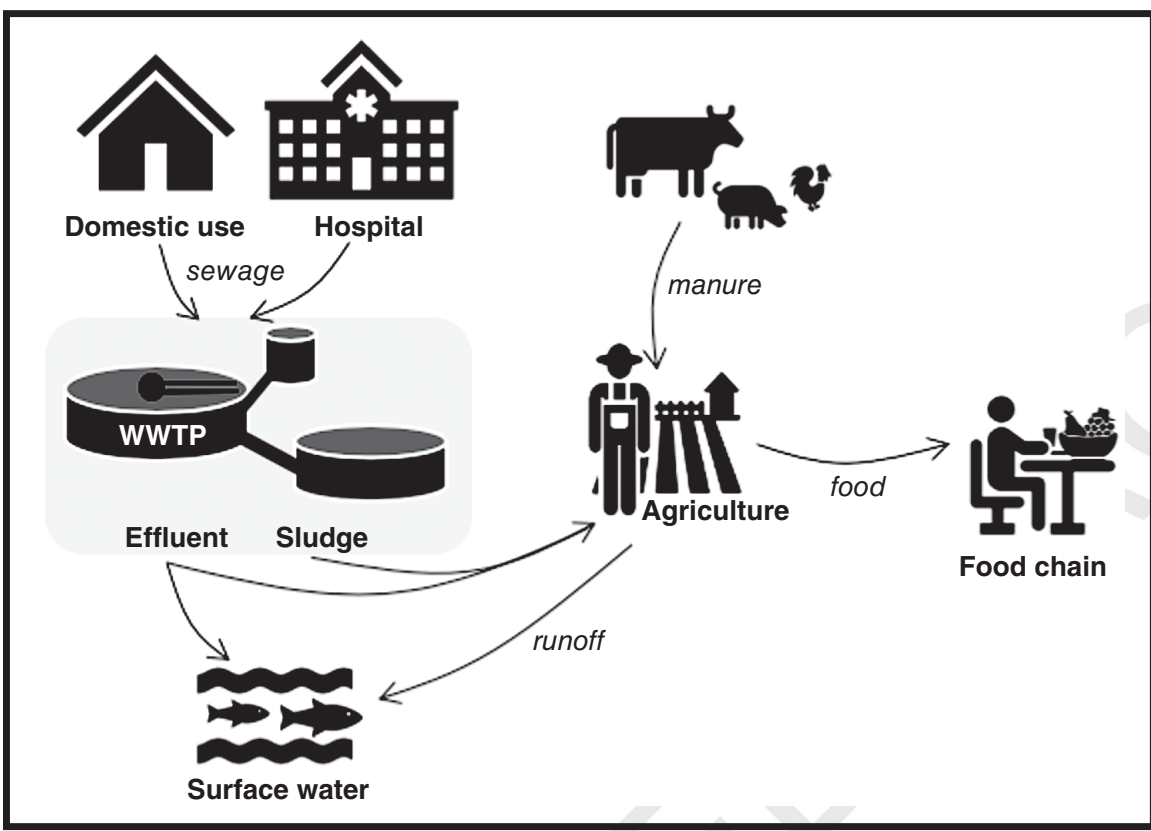

Figure 6.2 Origins of EOCs such as pharmaceuticals and routes into the environment.

and naproxen in carrots and sweet potatoes irrigated with treated wastewater. It is difficult to predict what environmental and public health implications may arise from the occurrence of these chemicals in the environment since EOCs are usually found in the environment at trace concentrations (i.e., between $\mathrm{ngl}^{-1}$ and $\mu \mathrm{gl}^{-1}$ or even lower). However, concerns are increasing about antimicrobial resistance [22] and chronic impacts on biodiversity, including endocrine-disrupting effects on fish [23-25]. Other effects/consequences of EOCs can be found summarized in the literature [10].

\subsubsection{EOCs in WWTPs}

Over the last two decades, the occurrence of several EOCs in the influents and treated effluents of WWTPs has been documented worldwide [3, 5, 11, 26]. In general, conventional WWTPs use a combination of primary (physical) and secondary (biological) methods. They were primarily designed to remove pathogens, suspended solids, and gross organic and inorganic matter, rather than remove the increasing numbers of new chemicals. Worldwide water scarcity is increasing the demand for non-conventional water resources. Nowadays, WWTPs have shown fairly limited effectiveness in EOC removal; there may still be significant concentrations of EOCs in effluents discharged into surface water bodies [27-29].

A combination of regulations and management measures with respect to discharging EOCs into the environment, as well as their occurrence in the environment, is fundamental to achieving efficient water resource management. Although there are no legal discharge limits for EOCs, some regulations have been published in the last 
few years. Actions have been initiated across Europe, but Switzerland is currently the only country regulating pharmaceuticals and micropollutants in wastewater. Switzerland also aims to remove a total of $50 \%$ of micropollutants by upgrading one-seventh of all wastewater plants to use activated carbon and ozonation by 2040 , as part of the Swiss micropollutants action plan ([30] and references therein).

Environmental quality standards for a minority of chemicals such as nonylphenol and bisphenol A have been stipulated in Directive 2008/105/EC. Nonylphenol and nonylphenol ethoxylates have also been recognized as toxic substances by the Canadian government [31]. Other EOCs, such as pharmaceutical and personal care products and steroid hormones, are not included in the list of regulated substances yet. To set regulatory limits, further research on biological responses to these compounds is needed [31].

Recent investigations have examined the fate of EOCs during wastewater treatment, focusing on their removal during conventional (e.g. activated sludge) and advanced (e.g. ozonation and membrane filtration) treatment processes. The results suggest that more studies in $\mathrm{EOC}_{\mathbf{\Lambda}}$ remediation should fill the knowledge gaps [10]. The water industry will most likely undergo several changes in the coming years due to rapid urbanization, severe climate change, rising customer demand, and the implementation of emerging digital technologies.

\subsubsection{Water Challenges}

Water is an essential resource for sustaining humanity and life in general. Access to water, sanitation, and hygiene is a human right; however, half the world's population experiences severe water scarcity at least one month a year [32]. Although approximately $70 \%$ of the Earth's surface is covered with water, only a small fraction (2.5\%) is freshwater compatible with terrestrial life. Nowadays, intensive pollution issues and, consequently, lack of water quality in many areas in the world have raised awareness about the importance of water. According to the European Environmental Agency Report, only around $40 \%$ of surface waters (rivers, lakes, and transitional and coastal waters) have a good ecological status or potential, and $38 \%$ have a good chemical status [33]. Nevertheless, effective strategies for addressing water contamination are latent in the modification and research of technologies aiming at wastewater treatment and integrating them into a holistic, circular water management system.

In this sense, various directives and protocols related to better water quality and management have been adopted in the last two decades. In 2000, the European Union (EU) introduced a list of 33 priority substances to control the chemical quality of water (Water Framework Directive, 2000/60/EC) [34], which was later updated to 45 substances in 2013 (Directive 2013/39/EU) [35].

According to the UN, the world population is expected to reach more than 9 billion people in 2050, and a continuous increase in water demand is observed as a consequence. The volume of wastewater generated by domestic, industrial, and commercial sources has been increasing along with population, urbanization, improved living conditions, and economic development [36]. At present, about 1 billion cubic meters of treated urban wastewater are reused annually, accounting 
for approximately $2.4 \%$ of treated urban wastewater effluents and less than $0.5 \%$ of annual EU freshwater withdrawals. To make sure there is enough food for the growing population, it is estimated that global food production needs to increase by $70 \%$; agriculture plays a key role and is a huge responsibility of water management, as it uses $70 \%$ of the available freshwater [37]. Thus, agricultural water consumption is also expected to grow by about $20 \%$ globally by 2050 [38]. In May 2018, the European Commission proposed new rules to stimulate and facilitate water reuse in the EU for agricultural irrigation [32]. The Regulation proposed by the Commission aims to alleviate water scarcity across the EU, and it will ensure that treated wastewater intended for agricultural irrigation is safe, protecting citizens and the environment. The proposal is part of the Commission's 2018 Work Programme, following up on the Circular Economy Action Plan, and completes the existing EU legal framework on water and foodstuffs.

Wastewater contains a great number of valuable resources such as nitrogen, phosphorus, energy, and other nutrients that can be recovered and reused in a circular economy to protect scarce and threatened resources in addition to reducing water consumption. However, changing from a linear model to a more circular economy requires rethinking traditional wastewater treatment models and understanding the interlinkages between the different Sustainable and Development Goals (SDGs). Some possible interlinkages that can be drawn from the SDG6 are shown in Figure 6.3. The SDG6 consists of the development of cost-efficient technologies to remove contaminants from wastewater, ensuring availability and sustainable management of water and sanitation for all. The SDG6 is an important element of the SDG2, promoting sustainable agricultural practices, as it will contribute to safe water reuse. At the same time, the SDG6 is also linked to other parts of Agenda 2030, such as those related to poverty, nutrition, health, education, gender,

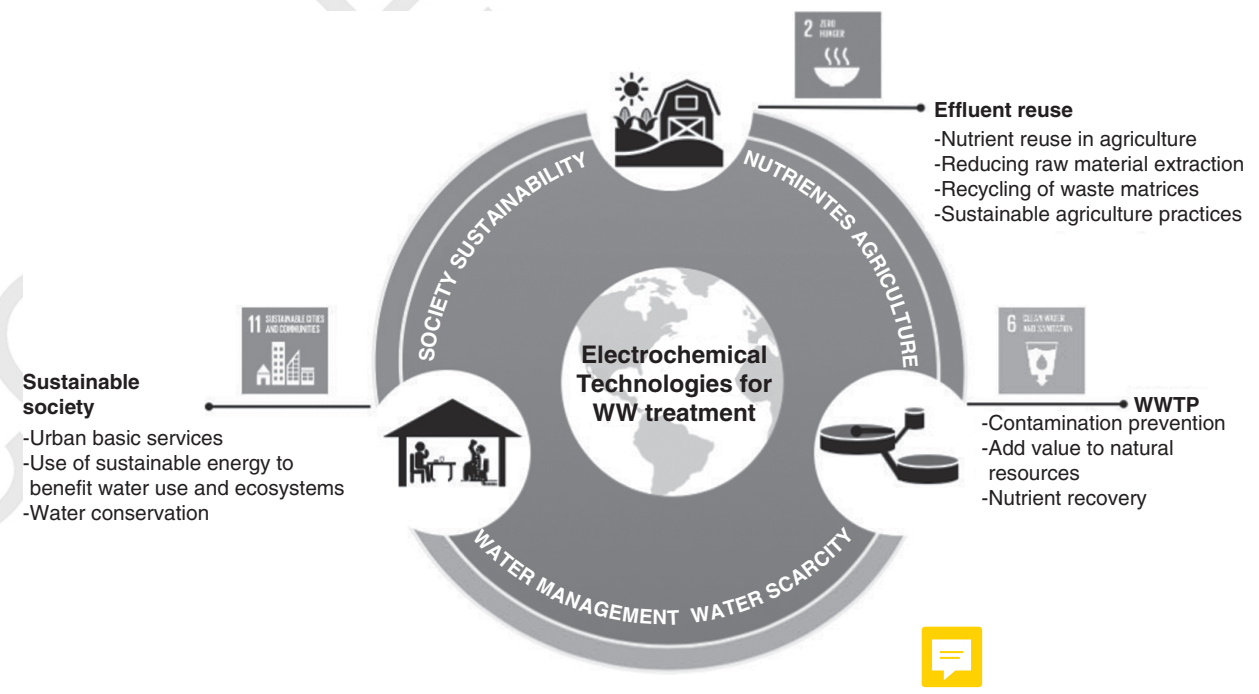

Figure 6.3 Interlink of Sustainable Development Goals addressing wastewater treatment challenges with electro-based technologies, 
6 | 6 Pharmaceutically Active Compounds in Wastewater Treatment Plants

economic growth, and climate change. Explicit links can be made between SDG6.2 and those relating to basic urban services, with the proportion of urban solid waste regularly collected and with adequate final discharge out of total urban solid waste generated by cities (SDG11). The relative importance of these interlinkages can vary based on regional or socio-economic context [39].

\subsubsection{Technologies for Wastewater Treatment - Electrochemical Process}

The treatment of urban wastewater is one of the biggest challenges of the twenty-first century, and the development of cheaper, effective, and novel methods of decontam ination is currently an active field of research, as shown by the numerous publications appearing each year (Figure 6.4).

In recent decades, research efforts have been made to develop more-effective technologies for the remediation of waters containing organic pollutants. Several physicochemical techniques have been exploited, such as activated carbon adsorption, advanced oxidation processes (AOPs), nanofiltration, reverse osmosis, and membrane bioreactors, to achieve high levels of ever, the application of such technologies implies a high cost for water treatment. In addition, these technologies in some cases do not achieve complete mineralization of the contaminant, sometimes leading to secondary pollution [41]. Successful mitigation strategies have not yet been established, and the search for alternative techniques is necessary to improve the degradation of organic contaminants (parent and secondary metabolites) and reduce the costs associated with effluent treatment in WWTPs, allowing its safe reuse [40, 42].

All the technologies have constraints not only in terms of cost but also in terms of feasibility, practicability, reliability, environmental impact, sludge production, operation difficulty, pretreatment requirements, and the formation of potentially toxic

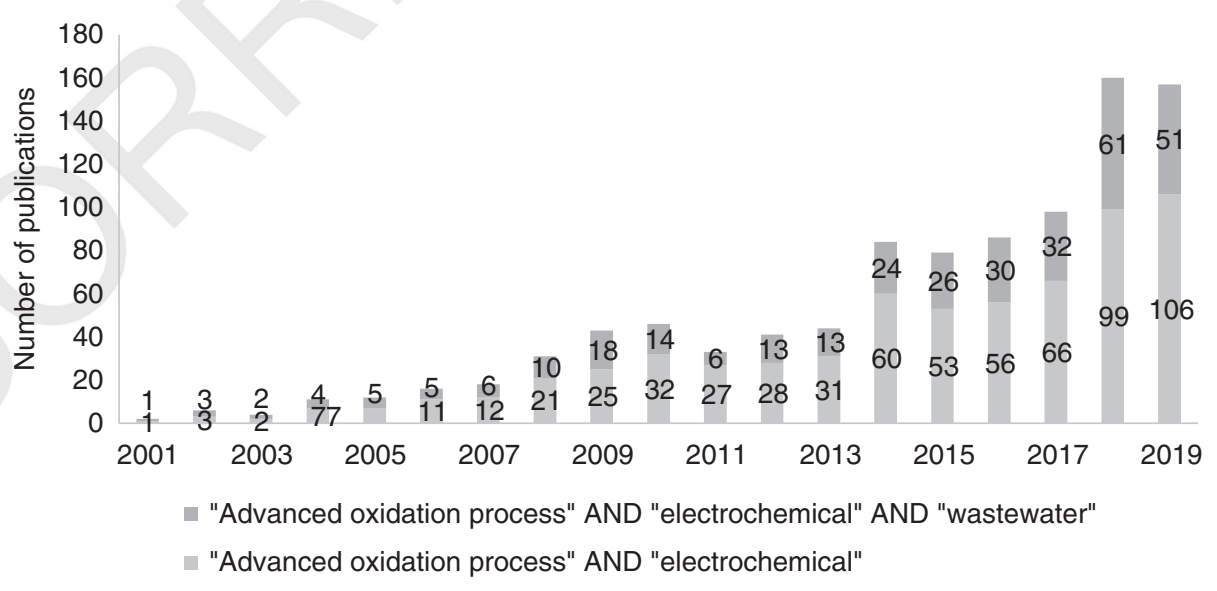

Figure 6.4 Number of publications from 2001 to 2019 on advanced oxidation processes with electrochemical technology and wastewater. 
byproducts. Among the various treatment processes currently cited for wastewater treatment, only a few are commonly employed by the industrial sector for technological and economic reasons [43].

The use of chemically strong oxidation agents such as hydroxyl radicals, chlorine, hydrogen peroxide, ozone, and combinations of these oxidants has been investigated for chemical oxidation of EOCs from wastewater. AOPs constitute important, promising, efficient, and environmentally friendly methods developed to principally remove organic pollutants from waters and wastewaters. Based on the ways oxidation agents are produced, AOPs can be classified in different ways such as Fenton oxidation catalytic ozonation, photocatalytic oxidation, and electrochemical oxidation [44].

Among the various technologies, the so-called electrochemical AOPs have generated increasing interest; over the last two decades, electrochemical technology or electrochemical-AOPs have gained increasing attention as a promising class of AOPs, representing half the publications in this field (Figure 6.4).

Electrochemical (EK) technology is a high-efficiency technology for oxidizing and removing a broad range of recalcitrant organic pollutants such as dyes, pesticides, herbicides, pharmaceuticals, antibiotics, hormones, chelating agents, and microcystin toxins [44-47]. EK processes have been investigated for wastewater treatment and offer a great advantage over conventional treatments since no additional chemicals are required as e.g. in electro-Fenton oxidation, and the electron may be considered as a "green" controllable reagent that does not generate sludge [48]. The great effectiveness of electrochemical methods is due to the production of the hydroxyl radical $\left({ }^{\bullet} \mathrm{OH}\right)$, which is a non-selective, very powerful oxidizing agent $(2.8 \mathrm{~V})$ that reacts with organics, giving dehydrogenated or hydroxylated derivatives until complete mineralization is reached [49]. Compared to other AOPs, electrochemicals are more efficient; for example, in [50], the study showed chemical oxygen demand (COD) degradation efficiency of $38.1 \%$, which is higher than that obtained using ozonation (17.0\%). Additionally, the specific energy demand is lower for electrochemical AOPs (93.6 kWh $/ \mathrm{kg} \mathrm{m} \mathrm{COD)} \mathrm{than} \mathrm{for} \mathrm{ozonation} \mathrm{(} 125.4 \mathrm{kWh} / \mathrm{kg} \mathrm{m} \mathrm{COD)}$ or the peroxone process $(134.5 \mathrm{kWh} / \mathrm{kg} \mathrm{m} \mathrm{COD})$.

The electrochemical oxidation of organic pollutants can take place in two ways: (i) direct electron exchange between the contaminant and the electrode surface, which can occur at relatively low potentials (i.e. prior to $\mathrm{O}_{2}$ evolution); or (ii) by indirect in situ electro generation of catalytic species, which relies on the production of oxidizing species at the electrode that mediate the transformation of contaminants. The rates of direct electrolysis are affected by diffusion limitations, slow reaction kinetics, and a decrease in the catalytic activity of the electrode in the presence of dissolved solutes (i.e. poisoning) [51].

The effectiveness of electrochemical oxidation of organic pollutants depends largely on the properties of the anode material, such as the $\mathrm{O}_{2}$ overpotential and adsorptive properties of the electrode surface [52-54]. Moreover, the reaction time, electrode separation distance, and electrode area might control the efficiency of EOC $C_{\Lambda}$ removal from wastewater [55]. 
8 8 6 Pharmaceutically Active Compounds in Wastewater Treatment Plants

Compared with conventional methods, the EK process has several advantages, such as ease of operation, short retention time, environmental compatibility, high-efficiency degradation, the potential for a high degree of automatization, robust performance, and the ability to adjust to variations in the influent composition and flow rate. However, the application of electrochemical treatment has been slowed by the relatively high costs of electrodes and concerns about toxic byproducts in the treated water [43].

\subsection{Electrochemical Reactor for EOC Removal in WWTPs}

A research study was carried out, aiming to investigate the electrooxidation performance of four different EOCs (Table 6.1) as a model for these experiments. The suitability of the electrode material and current density were studied, including sulfamethoxazole, carbamazepine, 17 $\alpha$-ethinylestradiol, and diclofenac from a real effluent sample. This investigation was undertaken to extend the knowledge of electro-degradation of EOCs in real effluents using different anode materials (graphite and Pt/Ti electrodes) and is part of the work carried out by the team and presented in [56]. The EOCs selected for the study include antibiotics, psychiatric drugs, hormones, and non-steroidal anti-inflammatory drugs that have been reported in rivers, lakes, and reservoirs around the world [10, 57-59]. In addition, all the EOCs present different physicochemical characteristics (e.g. solubility, octanol-water partition coefficient; Table 6.1) to give a representative study of EOC removal.

\subsubsection{Experimental Design}

Electrochemical experiments were carried out in a cylindrical reactor made of Plexiglas, $10 \mathrm{~cm}$ long and with an internal diameter of $8 \mathrm{~cm}$ (Figure 6.5). Electrodes were installed $2.5 \mathrm{~cm}$ from the middle of the reactor $(5 \mathrm{~cm}$ apart from each other). The power supply (Hewlett-Packard E3612A) was used to maintain constant DC.

The vertical reactor was tested in a continuous flow mode with effluent at $2 \mathrm{ml} \mathrm{min}{ }^{-1}$. Two different anode materials - Pt/Ti (platinized coated titanium; length $5.5 \mathrm{~cm}$, diameter $3 \mathrm{~mm}$; Permascand $\left.{ }^{\circ}\right)$ and graphite $(99.9995 \%$ metals basis; length $5.5 \mathrm{~cm}$, diameter $3 \mathrm{~mm}$; AlfaAesar) - were tested with a fixed Pt/Ti cathode. In addition to the effect of the anode material, two different current intensities were tested: $25 \mathrm{~mA}$ and $100 \mathrm{~mA}$. Before EK treatment, the effluent was spiked with $3 \mathrm{mg} \mathrm{l}^{-1}$ of each contaminant.

\subsubsection{Analytical Methodology}

Sulfamethoxazole, carbamazepine, diclofenac, and ethinylestradiol standards with high purity grade $(>97 \%$ ) were purchased from Sigma-Aldrich (Steinheim, Germany). The effluent samples were pre-cleaned/concentrated by soli-phase extraction (SPE) using Oasis HLB $500 \mathrm{mg}$ (Waters; Saint-Quentin En Yvelines Cedex, France). The cartridges were placed in an SPE manifold connected to a 
Table 6.1 Chemical structure and properties of emerging organic contaminants.

\begin{tabular}{|c|c|c|c|c|c|}
\hline EOCs & Formula & $\log K_{\text {ow }}$ & pKa & $\begin{array}{l}\text { Solubility } \\
\text { in water } \\
\left(\mathrm{mg} \mathrm{l}^{-1}\right)\end{array}$ & Category \\
\hline $\begin{array}{l}\text { Sulfamethoxazole } \\
\text { (SFM) }\end{array}$ & $\mathrm{C}_{10} \mathrm{H}_{11} \mathrm{~N}_{3} \mathrm{O}_{3} \mathrm{~S}$ & 0.89 & 5.7 & 610 & Antibiotic \\
\hline $\begin{array}{l}\text { Carbamazepine } \\
\text { (CBMP) }\end{array}$ & $\mathrm{C}_{15} \mathrm{H}_{12} \mathrm{~N}_{2} \mathrm{O}$ & 2.45 & 13.9 & 18 & Anticonvulsive \\
\hline $\begin{array}{l}\text { 17 } \alpha \text {-ethinylestradiol } \\
(\mathrm{EE} 2)\end{array}$ & $\mathrm{C}_{20} \mathrm{H}_{24} \mathrm{O}_{2}$ & 3.67 & 10.3 & 11.3 & Estrogen \\
\hline $\begin{array}{l}\text { Diclofenac } \\
\text { (DCF) }\end{array}$ & $\mathrm{C}_{14} \mathrm{H}_{11} \mathrm{Cl}_{2} \mathrm{NO}_{2}$ & 4.51 & 4.15 & 2.37 & Anti-inflammatory \\
\hline
\end{tabular}

Sources: PubChem, http://pubchem.ncbi.nlm.nih.gov; Sigma-Aldrich, Inc., www.SigmaAldrich .com.

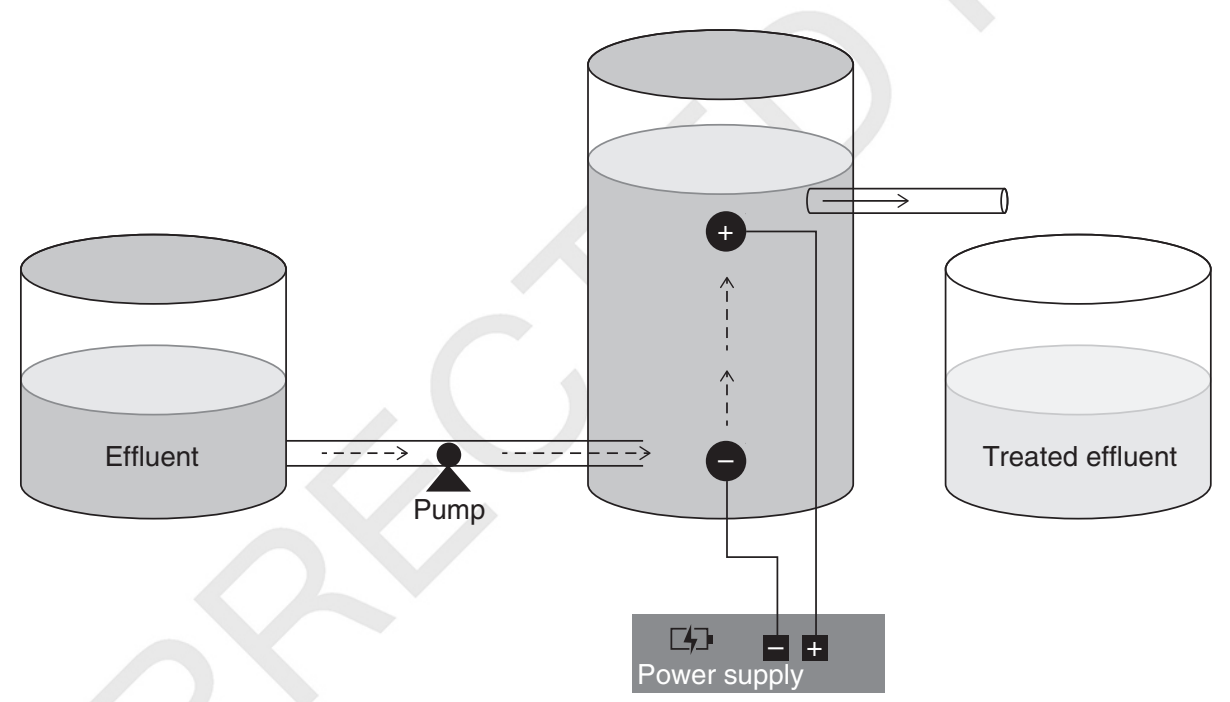

Figure 6.5 Electrochemical reactor design.

vacuum pump and operated as follows: conditioned by washing with $3 \times 6 \mathrm{ml}$ of $\mathrm{MeOH}$, followed by re-equilibrium with $3 \times 6 \mathrm{ml}$ of Milli-Q water; for EOC enrichment, samples were acidified to $\mathrm{pH} 2$ before extraction (nitric acid; deionized water, 1:1) and filtered through a $0.45 \mu \mathrm{m}$ MF filter; $200 \mathrm{ml}$ of the sample was passed through the cartridge at a flow rate of approximately $10 \mathrm{ml} \mathrm{min} \mathrm{m}^{-1}$; then, the cartridges were dried for about 2 minutes by vacuum; finally, the extracts were eluted with two $\times 6 \mathrm{ml}$ of $\mathrm{MeOH}$. The samples were filtered before analysis through FILTER-LAB ${ }^{\circ}$ polytetrafluoroethylene (PTFE) syringe filters (pore size $0.45 \mu \mathrm{m}$ ), previously passed through methanol. The EOC analysis was carried out by high-performance liquid chromatography (HPLC) with a diode array and fluorescence detectors (HPLC-DAD-FLD), 1260 Infinity II LC Systems (Agilent 1100 
Series Technologies, USA) equipped with a quaternary pump and auto-sampler (1260). The RP-18e column (Chromolith High Resolution, $100 \times 4.6 \mathrm{~mm}$; VWR, Darmstadt, Germany) was used for analyte separation. LC OpenLab software was used for data processing.

\subsubsection{Electrokinetic Reactor Operating in a Continuous Vertical Flow Mode}

The initial effluent sample presented an alkaline $\mathrm{pH}(\sim 8.6)$ and conductivity of $\sim 1.8 \mathrm{mS} \mathrm{cm}^{-1}$, and all the parameters were within the Portuguese legal limits for discharge into water bodies (DL 236/98). The $\mathrm{pH}$, conductivity, and voltage values after EK treatment are listed in Table 6.2. The $\mathrm{pH}$ of the effluent had the tendency to decreases lightly, primarily when the higher current intensity was tested and when a graphite anode was used. The conductivity slightly decreased for the lowest current intensity and remained constant when applying a higher current intensity due to the greater production of ions in the electrode. The presence of $\mathrm{Cl}^{-}$and other inorganic ions in the effluent yielded sufficient conductivity for direct EK treatment without adding any salt as supporting electrolyte. In both cases, using graphite or $\mathrm{Pt} / \mathrm{Ti}$ as an anode, the voltage increased when higher current intensity was applied due to greater hydroxide ion generation.

Figure 6.6 shows the removal of the selected EOCs after EK treatment with low current intensity $(25 \mathrm{~mA})$ and with the current intensity increased four times $(100 \mathrm{~mA})$ for the two anode materials tested. An initial effluent screening was carried out, and the concentration of the target EOCs was below the analytical detection limits.

Compared with a control (without applied current), the effect of the lowest current applied ( $25 \mathrm{~mA}$ ) promoted the removal of between 5 and $41 \%$ of EOCs; when the current intensity was increased to $100 \mathrm{~mA}$, removal increased 10-36\%. Regarding the differences among the contaminants for the two tested current intensities, CBMP and DCF showed the lowest level of removal. The compound's molecular structure has a strong influence on the success of electrochemical removal. Compounds characterized by the presence of electrophilic halogen groups with a negative inductive effect at the aromatic ring or by the absence of nucleophilic substituents with an activating effect on the aromatic ring like DCF are more recalcitrant because they

Table 6.2 pH, conductivity, and voltage drop after EK treatment.

\begin{tabular}{lllcl}
\hline $\begin{array}{l}\text { Current intensity } \\
(\mathrm{mA})\end{array}$ & Anode & $\mathbf{p H}$ & Conductivity $\left(\mathrm{mS} \mathrm{cm}^{-1}\right)$ & Voltage (V) \\
\hline 25 & Graphite & 8.11 & 1.72 & $7.2-7.0$ \\
& Pt/Ti & 8.51 & 1.63 & $6.9-7.0$ \\
100 & Graphite & 7.25 & 1.85 & $14.8-16.7$ \\
& Pt/Ti & 7.46 & 1.85 & $14.8-16.4$ \\
\hline
\end{tabular}




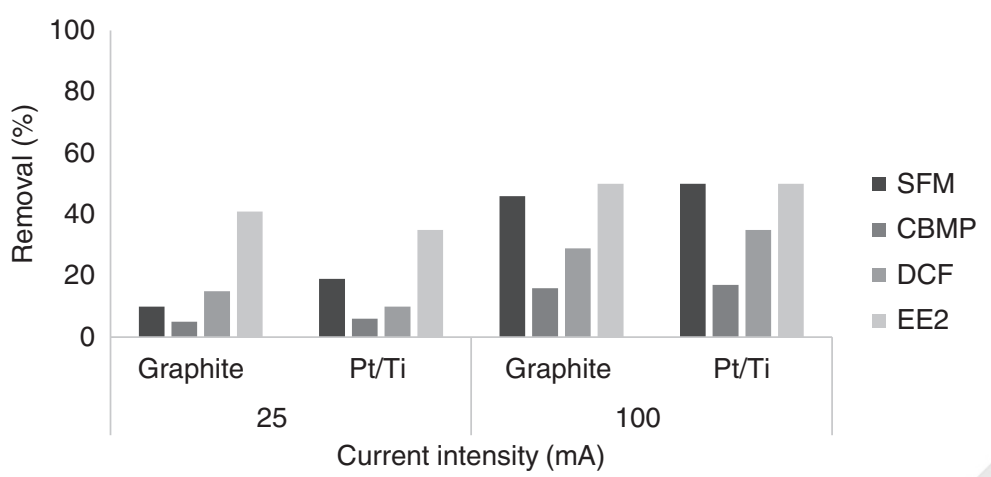

Figure 6.6 Removal (\%) of EOCs after electrochemical treatment in a vertical continuous-flow reactor, applying different current intensities and anode materials.

decrease the reactivity toward oxidant agents and active chlorine species present in effluents [60].

\section{- Current intensity}

In several studies, current intensity is reported to affect electrochemical oxidation efficiency as it is the driving force of the reaction. The results from this study showed that EOC removal was enhanced by increasing current intensity. SFM removal increased by $36 \%$ when $100 \mathrm{~mA}$ were applied. Increasing current intensity promotes the generation of more $\mathrm{OH}$, which is responsible for organic oxidation; hence, greater EOC removal can be expected in the tested conditions. Other research also found that an increase in current intensity enhances contaminant removal. For example, in [61], the effect of current density on the removal rate of COD of wastewater with sulfamethoxazole and trimethoprim (two well-known antibiotics) was investigated, and the results showed that COD removal efficiency increased when the current density increased from 10 to $100 \mathrm{~mA} \mathrm{~cm}^{-2}$. However, when increased indefinitely, the current during EK treatment is not always proportional to the removal rate. The rate of parasitic reactions is also promoted, which leads to decreasing current efficiency and, consequently, less contaminant removal [47]. It is important to regular the amount of oxidizing species produced, taking into account the feasibility of the process in terms of electrical charge consumed and/or energy consumption [47]. In addition to energy dissipation, high current intensities can shorten the lifetime of the electrodes [62].

\section{- Anode material}

To improve process efficiency, several anode materials have been tested and show varied performance. In the tested conditions, no differences were found in terms of EOC degradation for the two tested anode materials, graphite and Pt/Ti. EK uses the electron as the primary reagent for contaminant removal: the generation of $\bullet \mathrm{OH}$ from water oxidation at anode is crucial for EOC $\mathrm{C}_{\mathbf{\Lambda}}$ removal. Graphite and $\mathrm{Pt} / \mathrm{Ti}$ are both considered active electrodes [63], and the electrogenerated $\bullet \mathrm{OH}$ is expected to be converted in "adsorbed oxygen," which is consumed in the oxidation of organic compounds with the formation of selective oxidation products and 
in an easy oxygen evolution [64]. Even though no differences were found between the two anodes in the tested conditions, the Pt electrode showed better performance than graphite. Some differences were also found for SFM and DCF removal in previous research such as [65]. The authors attributed the differences to the different adsorptions of ${ }^{\bullet} \mathrm{OH}$ on these electrodes: due to Pt, the ${ }^{\bullet} \mathrm{OH}$ are weakly adsorbed and have lower adsorption on the Pt surface. Consequently, they are very reactive and effective toward oxidation due to the faster reactions with all organics arriving at the surface and in the anode's vicinity. On the other hand, graphite has more ${ }^{\bullet} \mathrm{OH}$ strongly adsorbed on its surface; thus it is less reactive toward $\mathrm{EOC}_{\perp}$ degradation [65].

After EK treatment, the graphite electrode showed signs of corrosion due to the effect of the applied current. Higher current could lead to electric energy transfer to thermal energy and result in a larger invalid consumption of the given charge. Even though high current intensity caused the electrode material to corrode, side reactions including oxygen evolution could also happen simultaneously, and no differences between the two electrodes in terms of EOC removal were registered for the tested conditions [66].

\section{- Flow mode}

The effect of current intensity can also be related to the continuous flow mode present in this work, which according to [64] is strongly interrelated, so they must be considered together. A continuous flow mode influences the direct oxidation of EOCs by the contact between electrode and effluent solution. In the vertical EK flow reactor, the effluent was in a continuous flow mode, passing first through the $\mathrm{Pt} / \mathrm{Ti}$ cathode electrode, where reduction reactions take place, and going toward the anode, where ${ }^{\bullet} \mathrm{OH}$ is generated. The oxidation of the organics by ${ }^{\bullet} \mathrm{OH}$ generated from the water oxidation is so fast that the rate-determining step is the mass transport from the bulk solution to the anodic surface. When the rate of the mass transfer of the organic to the anodic surface is dramatically lower than the rate of oxidation, the concentration of the pollutant at the anodic surface/reaction layer is close to zero, and the oxidation process is under mass-transfer control [64]. Considering that the electrochemical oxidation of organics is limited by mass transport, high flow rates in the reactor might increase the mass transfer, thus allowing enhanced performance. If oxidation takes place by indirect electrolysis, high flow rates are reported to favor removal, meaning the oxidation is a diffusion-controlled process [67].

The present results showed that electrochemical degradation is a promising method for EOC removal, but operational parameters need to be optimized: for example, by changing the flow mode and current intensity and testing different electrode materials. Experiments in batch mode were carried out by the team, and greater removal (> 90\%) was achieved [56]. The results presented in [56] also show that in addition to the influence of the batch and flow mode, the electrode shape and material are key to a cost-efficient process. Greater EOC removal was achieved in a batch-mode system, with both the electrode's shape and material proving to be important parameters to improve the EK process, not only for 
removing EOCs but also to make the process more efficient in terms of energy consumption.

\subsection{Conclusions}

To limit the presence of EOCs in the environment, efficient technologies should be implemented in WWTPs and stricter environmental quality standards should be established. The removal of EOCs with different physicochemical characteristics represents a real challenge in wastewater treatment. Research of electrochemical technologies to remove EOCs has been increasing, and the results show that treatment efficiency depends on reactor design and operational parameters such as flow mode and electrode material. The use of electrochemical technologies to remove EOCs from wastewater is a promising technology with the potential to reduce the environmental and human risks associated with the spread of contamination.

\section{Acknowledgments}

Financial support was provided by 4KET4Reuse (SOE1/P1/E0253) and CEMOWAS 2 (SOE2/P5/F0505), co-financed by the European Regional Development Fund (FEDER), the European Union's Horizon 2020 research and innovation program under the Marie Skłodowska-Curie grant agreement No. 778045; FCT/MCTES, Portugal, through UIDB/04085/2020 (research unit CENSE, Center for Environmental and Sustainability Research). Fundação para a Ciência e a Tecnologia is also acknowledged for P. Guedes' fellowship (SFRH/BPD/114660/2016) and N. Couto's contract established under the Individual Call to Scientific Employment Stimulus (CEECIND/04210/2017). The authors acknowledge and appreciate the support given to CENSE by the Portuguese Foundation for Science and Technology (FCT) through the strategic project UIDB/04085/2020. The authors would like to thank SIMARSUL, Dr. Cristina Santos, and Eng. Olga Paredes for providing the effluent samples, and the Laboratory of Control and Processes for assistance. This research is anchored by the RESOLUTION LAB, an infrastructure at NOVA School of Science and Technology.

\section{References}

1 Naidu, R., Jit, J., Kennedy, B., and Arias, V. (2016). Emerging contaminant uncertainties and policy: the chicken or the egg conundrum. Chemosphere 154: 385-390.

2 Sauvé, S. and Desrosiers, M. (2014). A review of what is an emerging contaminant. Chemistry Central Journal 8: 15. 
3 Ebele, A.J., Abou-Elwafa Abdallah, M., and Harrad, S. (2017). Pharmaceuticals and personal care products (PPCPs) in the freshwater aquatic environment. Emerging Contaminants 3 (1): 1-16.

4 Khetan, S.K. and Collins, T.J. (2007). Human Pharmaceuticals in the Aquatic Environment: a challenge to green chemistry. Chemical Reviews 107 (6): 2319-2364.

5 Richardson, B.J., Lam, P.K.S., and Martin, M. (2005). Emerging chemicals of concern: pharmaceuticals and personal care products (PPCPs) in Asia, with particular reference to southern China. Marine Pollution Bulletin 50 (9): 913-920.

6 Li, M., Sun, Q., Li, Y. et al. (2016). Simultaneous analysis of 45 pharmaceuticals and personal care products in sludge by matrix solid-phase dispersion and liquid chromatography tandem mass spectrometry. Analytical and Bioanalytical Chemistry 408 (18): 4953-4964.

7 Barceló, D. and Petrovic, M. (2007). Pharmaceuticals and personal care products (PPCPs) in the environment. Analytical and Bioanalytical Chemistry 387 (4): 1141-1142.

8 Buchberger, W. (2011). Current approaches to trace analysis of pharmaceuticals and personal care products in the environment. Journal of Chromatography $A$ 1218 (4): 603-618.

9 Archer, E., Petrie, B., Kasprzyk-Hordern, B., and Wolfaardt, G.M. (2017). The fate of pharmaceuticals and personal care products (PPCPs), endocrine disrupting contaminants (EDCs), metabolites and illicit drugs in a WWTW and environmental waters. Chemosphere 174: 437-446.

10 Gogoi, A., Mazumder, P., Tyagi, V.K. et al. (2018). Occurrence and fate of emerging contaminants in water environment: a review. Groundwater for Sustainable Development 6: 169-180.

11 Heberer, T. (2002). Occurrence, fate, and removal of pharmaceutical residues in the aquatic environment: a review of recent research data. Toxicology Letters 131 (1-2): 5-17.

12 Mompelat, S., Le Bot, B., and Thomas, O. (2009). Occurrence and fate of pharmaceutical products and byproducts, from resource to drinking water. Environment International 35 (5): 803-814.

13 A, L.G. and Pettigrove, M.E. (2006). Seasonal variations in concentrations of pharmaceuticals and personal care products in drinking water and reclaimed wastewater in southern California. Environmental Science and Technology 40 (3): 687-695.

14 Couto, N., Ferreira, A.R., Guedes, P. et al. (2018). Partition and remediation potential of caffeine, oxybenzone and triclosan in estuarine environment. Environmental Science and Pollution Research 25 (36): 35928-35935.

15 Grassi, M., Rizzo, L., and Farina, A. (2013). Endocrine disruptors compounds, pharmaceuticals and personal care products in urban wastewater: implications for agricultural reuse and their removal by adsorption process. Environmental Science and Pollution Research 20 (6): 3616-3628. 
16 Zhang, D., Gersberg, R.M., Ng, W.J., and Tan, S.K. (2013). Removal of pharmaceuticals and personal care products in aquatic plant-based systems: a review. Environmental Pollution 184: 620-639.

17 Biel-Maeso, M., Corada-Fernández, C., and Lara-Martín, P.A. (2018). Monitoring the occurrence of pharmaceuticals in soils irrigated with reclaimed wastewater. Environmental Pollution 235: 312-321.

18 Calderón-Preciado, D., Jiménez-Cartagena, C., Matamoros, V., and Bayona, J.M. (2011). Screening of 47 organic microcontaminants in agricultural irrigation waters and their soil loading. Water Research 45 (1): 221-231.

19 Paltiel, O., Fedorova, G., Tadmor, G. et al. (2016). Human exposure to wastewater-derived pharmaceuticals in fresh produce: a randomized controlled trial focusing on carbamazepine. Environmental Science and Technology 50 (8): 4476-4482.

20 Hurtado, C., Domínguez, C., Pérez-Babace, L. et al. (2016). Estimate of uptake and translocation of emerging organic contaminants from irrigation water concentration in lettuce grown under controlled conditions. Journal of Hazardous Materials 305: 139-148.

21 Malchi, T., Maor, Y., Tadmor, G. et al. (2014). Irrigation of root vegetables with treated wastewater: evaluating uptake of pharmaceuticals and the associated human health risks. Environmental Science and Technology 48 (16): 9325-9333.

22 Piña, B., Bayona, J.M., Christou, A. et al. (2018). On the contribution of reclaimed wastewater irrigation to the potential exposure of humans to antibiotics, antibiotic resistant bacteria and antibiotic resistance genes - NEREUS COST action ES1403 position paper. Journal of Environmental Chemical Engineering 8 (1): 102131.

23 Meador, J.P., Yeh, A., Young, G., and Gallagher, E.P. (2016). Contaminants of emerging concern in a large temperate estuary. Environmental Pollution 213: 254-267.

24 Rosal, R., Rodea-Palomares, I., Boltes, K. et al. (2010). Ecotoxicity assessment of lipid regulators in water and biologically treated wastewater using three aquatic organisms. Environmental Science and Pollution Research 17 (1): 135-144.

25 Cunha, V., Burkhardt-Medicke, K., Wellner, P. et al. (2017). Effects of pharmaceuticals and personal care products (PPCPs) on multixenobiotic resistance (MXR) related efflux transporter activity in zebrafish (Danio rerio) embryos. Ecotoxicology and Environmental Safety 136: 14-23.

26 Boyd, G.R., Reemtsma, H., DA, G., and Mitra, S. (2003). Pharmaceuticals and personal care products (PPCPs) in surface and treated waters of Louisiana, USA and Ontario, Canada. The Science of the Total Environment 311 (03): 135-149.

27 Verlicchi, P., Al Aukidy, M., and Zambello, E. (2012). Occurrence of pharmaceutical compounds in urban wastewater: removal, mass load and environmental risk after a secondary treatment-a review. The Science of the Total Environment 429: 123-155. 
28 Petrie, B., Barden, R., and Kasprzyk-Hordern, B. (2014). A review on emerging contaminants in wastewaters and the environment: current knowledge, understudied areas and recommendations for future monitoring. Water Research 72: 3-27.

29 De Jesus, G.V., Cardoso, V.V., Cardoso, E. et al. (2017). Occurrence and behaviour of pharmaceutical compounds in a Portuguese wastewater treatment plant: removal efficiency through conventional treatment processes. Environmental Science and Pollution Research 24 (17): 14717-14734.

30 European Federation of National Associations of Water Services, EurEau. (2019). Briefing note - Treating micropollutants at waste water treatment plants. 2019. http://www.eureau.org/resources/briefing-notes/3826-briefing-note-on-treatingmicropollutants-at-the-wwtp/file.

31 Canadian Environmental Protection Act. (1999). Priority substances list assessment report, "nonylphenol and its ethoxylates".

32 European Comission. (2018). Environment. Water reuse. http://ec.europa.eu/ environment/water/reuse.htm.

33 Kristensen, P., Whalley, C., and Klančnik, K. (2018). European waters assessment of status and pressures 2018. European Environment Agency. https://www.eea .europa.eu/publications/state-of-water.

34 EU (2000). Directive 2000/60/EC of the European Parliament and of the council establishing a framework for community action in the field of water policy off. Journal of the European Communities 327: 1-72.

35 EU (2013). Directive 2013/39/EU of the European Parliament and of the council amending directives 2000/60/EC and 2008/105/EC as regards priority substances in the field of water policy off. Journal of the European Communities 226: 1-17.

36 Qadir, M., Wichelns, D., Raschid-Sally, L. et al. (2010). The challenges of wastewater irrigation in developing countries. Agricultural Water Management 97 (4): 561-568.

37 Food and Agriculture Organization of the United Nations (FAO). (2018). Proportion of total water withdrawal withdrawn for agriculture (\%). http://www.fao.org/ $\mathrm{nr} /$ water/aquastat/maps/World-Map.WithA.Twith_eng.htm.

38 United Nations Department of Economic and Social Affairs. (2015). World population prospects: The 2015 revision. http://www.un.org/en/development/desa/ news/population/2015-report.html.

39 Fritsche, U.R., Eppler, U., Fehrenbach, H., and Giegrich, J. (2018). Linkages between the Sustainable Development Goals (SDGs) and the GBEP Sustainability Indicators for Bioenergy (GSI). Global Bioenergy Partnership. http://www .globalbioenergy.org/fileadmin/user_upload/gbep/docs/Indicators/IINAS_IFEU_ 2018_Linkages_SDGs_and_GSIs_-_final.pdf.

40 Luo, Y., Guo, W., Ngo, H.H. et al. (2014). A review on the occurrence of micropollutants in the aquatic environment and their fate and removal during wastewater treatment. The Science of the Total Environment 473-474: 619-641.

41 Martínez-Huitle, C.A. and Ferro, S. (2016). Electrochemical oxidation of organic pollutants for the wastewater treatment: direct and indirect processes. Chemical Society Reviews 35: 1324-1340. 
42 Schröder, P., Helmreich, B., Škrbić, B. et al. (2016). Status of hormones and painkillers in wastewater effluents across several European states-considerations for the EU watch list concerning estradiols and diclofenac. Environmental Science and Pollution Research 23 (13): 12835-12866.

43 Crini, G. and Lichtfouse, E. (2019). Advantages and disadvantages of techniques used for wastewater treatment. Environmental Chemistry Letters 17 (1): 145-155.

44 Ghime, D. and Ghosh, P. (2019). Removal of organic compounds found in the wastewater through electrochemical advanced oxidation processes: a review. Russian Journal of Electrochemistry 55 (7): 591-620.

45 Couto, N., Guedes, P., Ferreira, A.R. et al. (2015). Electrodialytic process of nanofiltration concentrates - phosphorus recovery and microcystins removal. Electrochimica Acta 181: 200-207.

46 Ai, Z., Li, J., Zhang, L., and Lee, S. (2010). Rapid decolorization of azo dyes in aqueous solution by an ultrasound-assisted electrocatalytic oxidation process. Ultrasonics Sonochemistry 17 (2): 370-375.

47 Moreira, F.C., Boaventura, R.A.R., Brillas, E., and Vilar, V.J.P. (2017). Electrochemical advanced oxidation processes: a review on their application to synthetic and real wastewaters. Applied Catalysis B: Environmental 202: 217-261.

48 Chu, Y.Y., Qian, Y., Wang, W.J., and Deng, X.L. (2012). A dual-cathode electro-Fenton oxidation coupled with anodic oxidation system used for 4-nitrophenol degradation. Journal of Hazardous Materials 199-200: 179-185.

49 Tung, C., Shen, S., Chang, J. et al. (2013). Treatment of real printing wastewater with an electrocatalytic process. Separation and Purification Technology 117: $131-136$

50 Haupt, D., Muddemann, T., Kunz, U., and Sievers, M. (2019). Evaluation of a new electrochemical concept for vacuum toilet wastewater treatment - comparison with ozonation and peroxone processes. Electrochemistry Communications 101: 115-119.

51 Wu, W., Huang, Z.-H., and Lim, T.-T. (2014). Recent development of mixed metal oxide anodes for electrochemical oxidation of organic pollutants in water. Applied Catalysis A: General 480: 58-78.

52 Cui, Y., Li, X., and Chen, G. (2009). Electrochemical degradation of bisphenol a on different anodes. Water Research 43 (7): 1968-1976.

53 Feng, L., Oturan, N., van Hullebusch, E.D. et al. (2014). Degradation of anti-inflammatory drug ketoprofen by electro-oxidation: comparison of electro-Fenton and anodic oxidation processes. Environmental Science and Pollution Research 21 (14): 8406-8416.

$54 \mathrm{Li}$, X., Cui, Y., Feng, Y. et al. (2005). Reaction pathways and mechanisms of the electrochemical degradation of phenol on different electrodes. Water Research 39 (10): 1972-1981.

55 González, T., Domínguez, J.R., Palo, P. et al. (2011). Development and optimization of the BDD-electrochemical oxidation of the antibiotic trimethoprim in aqueous solution. Desalination 280 (1-3): 197-202. 
56 Ferreira, A.R. (2018). Electro-based technologies for contaminants removal from soil and effluent targeting further reuses. PhD thesis, NOVA School of Science and Technology, NOVA University Lisbon.

57 Kolpin, D.W., Furlong, E.T., Meyer, M.T. et al. (2002). Pharmaceuticals, hormones, and other organic wastewater contaminants in U.S. streams, 1999-2000: a national reconnaissance. Environmental Science \& Technology 36 (6): 1202-1211.

58 Paíga, P., Correia, M., Fernandes, M.J. et al. (2019). Assessment of 83 pharmaceuticals in WWTP influent and effluent samples by UHPLC-MS/MS: hourly variation. Science of the Total Environment 648: 582-600.

59 Oulton, R.L., Kohn, T., and Cwiertny, D.M. (2010). Pharmaceuticals and personal care products in effluent matrices: a survey of transformation and removal during wastewater treatment and implications for wastewater management. Journal of Environmental Monitoring 12 (11): 1956.

60 Garcia-Segura, S., Keller, J., Brillas, E., and Radjenovic, J. (2015). Removal of organic contaminants from secondary effluent by anodic oxidation with a boron-doped diamond anode as tertiary treatment. Journal of Hazardous Materials 283: 551-557.

61 Eleotério, I.C., Forti, J.C., and de Andrade, A.R. (2013). Electrochemical treatment of wastewater of veterinary industry containing antibiotics. Electrocatalysis 4 (4): 283-289.

62 Niu, J., Li, Y., Shang, E. et al. (2016). Electrochemical oxidation of perfluorinated compounds in water. Chemosphere 146: 526-538.

63 Rivera-Utrilla, J., Sánchez-Polo, M., Ferro-García, M.Á. et al. (2013). Pharmaceuticals as emerging contaminants and their removal from water. A review. Chemosphere 93 (7): 1268-1287.

64 Scialdone, O., Galia, A., and Randazzo, S. (2011). Oxidation of carboxylic acids in water at $\mathrm{IrO}_{2}-\mathrm{Ta}_{2} \mathrm{O}_{5}$ and boron doped diamond anodes. Chemical Engineering Journal 174 (1): 266-274.

65 Sifuna, F.W., Orata, F., Okello, V., and Jemutai-Kimosop, S. (2016; 18;). Comparative studies in electrochemical degradation of sulfamethoxazole and diclofenac in water by using various electrodes and phosphate and sulfate supporting electrolytes. Journal of Environmental Science and Health, Part A 51 (11): 954-961.

66 Marselli, B., Garcia-Gomez, J., Michaud, P.-A. et al. (2003). Electrogeneration of hydroxyl radicals on boron-doped diamond electrodes. Journal of the Electrochemical Society 150 (3): D79.

67 Panizza, M., Barbucci, A., Ricotti, R., and Cerisola, G. (2007). Electrochemical degradation of methylene blue. Separation and Purification Technology 54 (3): 382-387. 


\section{Author Queries}

\begin{tabular}{l|l} 
AQ1 & We have shortened running head as it exceeds hsize value.
\end{tabular}

Please check if this is fine. 